\title{
Autoria tecnocientífica no Ensino Fundamental: a investigação-ação-participativa no ensino de ciências
}

\author{
Roberth De-Carvalho ${ }^{1,2}$ (D) \& Igor Augusto Garcia ${ }^{3}$ (D)
}

(1) Instituto Federal de Santa Catarina - Campus Florianópolis, Avenida Mauro Ramos 950, Centro 88020300, Florianópolis, Santa Catarina, Brasil. E-mail: orientador.roberth@gmail.com

(2) Universidade Federal de Santa Catarina - Campus Universitário Trindade, Centro de Ciências da Educação, Programa de Pós-Graduação em Educação Científica e Tecnológica, Rua Roberto Sampaio Gonzaga, Trindade 88040-900, Florianópolis, Santa Catarina, Brasil.

(3) Secretaria Municipal de Educação, Rua Conselheiro Mafra 656, Centro 88010-914, Florianópolis, Santa Catarina, Brasil. E-mail: professorigorgarcia@hotmail.com

De-Carvalho R. \& Garcia I.A. (2020) Autoria tecnocientífica no Ensino Fundamental: a investigação-açãoparticipativa no ensino de ciências. Pesquisa e Ensino em Ciências Exatas e da Natureza, 4: e1587. http://dx.doi.org/10.29215/pecen.v4i0.1587

Editor acadêmico: Diego Marceli Rocha. Recebido: 22 julho 2020. Aceito: 08 dezembro 2020. Publicado: 15 dezembro 2020.

Resumo: Processos pedagógicos profissionais (p.p.p.) organizam ambientes metodológicos em plena dialogicidade entre componentes pessoais (estudantes e demais sujeitos escolares ou não) e não-pessoais (direcionamentos pedagógicos). Em um ambiente de Ensino Fundamental, mediamos a construção de autoria tecnocientífica de um grupo de estudantes do $9^{\circ}$ ano da rede pública de Florianópolis, Santa Catarina. Esse processo se deu em torno do trabalho editorial para uma revista de divulgação científica com conteúdos de Física, no qual ressaltaram uma identidade coletiva na formação de discursos de ciênciatecnologia-sociedade (CTS). Pela metodologia de investigação-ação-participativa (IAP), na perspectiva colombiana de Fals Borda (1925-2008), avaliamos uma sinergia entre diálogos de saberes locais e científicos daqueles/as estudantes. Pressupostos pedagógicos decoloniais afirmaram um sistema de linguagens e discursos para uma educação em ciências de natureza libertadora e autoral.

Palavras chave: Produção editorial, sentido coletivo, discurso CTS, pesquisa-ação.

Technoscientific authorship in Elementary School: the participatory action-research in science teaching

Abstract: Profesional pedagogical processes (p.p.p.) organize methodological environments that point out them in dialogicity absolute among personal components (students and others schoolar subjects or no) and no-personal (pedagogical orientations). In an environment of Elementary School, we had mediated the making of technoscientific authorship from a group of students in $9^{\text {th }}$. stage, in a public school of Florianópolis city, Santa Catarina. This process happened around the editorial work for a scientific magazine with Physics contents, in wich they showed a collective identity in the formation of sciencetechnology-society (STS) discourses. By the participatory action-research (PAR), in the Fals Borda's (19252008) Colombian approach, we had evaluated a sinergy among dialogues of local and scientific knowledges. Decolonial pedagogical assumptions claimed a language and discourse system for a scientific education of liberator and authorial nature.

Key words: Editorial production, collective sense, STS discourse, research-action.

\section{Introdução}

O trabalho docente na escola básica se reitera dialeticamente aos pares: método/conteúdo e objetivo/avaliação (cf. Freitas 2014). E, se tomarmos a diversidade 
sociocultural contida nas linguagens que emerge dos referidos componentes, em nível pessoal (estudantes e demais sujeitos escolares ou não) e não-pessoal (concepções/direcionamentos pedagógicos dados aos pares dialéticos), podemos qualificar nosso quefazer (Freire 2013, 2017) docente por pequenos recortes curriculares tecnocientíficos capazes de validar relevantes sentidos coletivos nas e pelas aprendizagens dos/as estudantes.

Assim, é importante um olhar atento do/a professor/a de Ciências para o meio sociocultural em que se insere a escola, quanto às prerrogativas do ser e do saber de estudantes (gestos, mitos, crêndices, línguas, ancestralidades, pertencimentos étnicos, orientações de gênero e sexualidade), variáveis mobilizadoras na produção de sentidos tecnocientíficos. Estas, quando silenciadas/interditadas na aprendizagem escolar, neutralizam sentidos de mundo no pensamento-linguagem de estudantes da escola básica, dependendo da abordagem escolhida pelo/a professor/a.

Com esse cuidado, tomamos como campo discursivo privilegiado a epistemologia de inter-relações ciência-tecnologia-sociedade (CTS) na educação em ciências, uma vez que "O campo da Educação CTS, em especial, vem sendo construído a partir de marcos conceituais e inovações curriculares que apontam para a necessidade de desenvolver educação científica e tecnológica contextualizada, crítica, cidadã e socialmente comprometida." (Jacinski et al. 2019: 196). Foco privilegiado de pesquisas e estudos CTS latino-americanos na educação em ciências, sob apreço das pedagogias do educador Paulo Freire, pode ser registrado na autoria de professores-pesquisadores do Ensino de Ciências, como: Auler et al. (2005), Auler \& Delizoicov (2006), Auler (2007), Von Linsingen (2007), Cassiani \& Von Linsingen (2010), Correa \& Bazzo (2017), Busko \& De-Carvalho (2019), Oliveira \& Von Linsingen (2019), Rodrigues et al. (2019), Jacinski et al. (ibid.), dentre outros.

\footnotetext{
[...] pelo enfoque Ciência, Tecnologia e Sociedade (CTS), que, dentre outros, busca favorecer o desenvolvimento e a consolidação de atitudes e práticas democráticas nas questões de importância social, assim como contribuir para a eliminação do crescente abismo que vem se consolidando entre a cultura humanista e a cultura científico-tecnológica ou exclusivamente econômica (Bazzo et al. 2008 apud Correa \& Bazzo 2017: 61).
}

Dessa perspectiva, compreendemos o funcionamento da linguagem na educação em ciências, em que levantamos o problema dessa pesquisa, a saber: como promover autorias tecnocientíficas pelos sentidos coletivos em estudantes da Educação Básica? Objetivamos, assim, propor um ambiente de funcionamento da linguagem pelo caminho da divulgação científica realizada por estudantes de $9^{\circ}$ ano do Ensino Fundamental, numa escola da rede pública, em Florianópolis, Santa Catarina.

\section{Autoria tecnocientífica em discursos CTS}

A construção de sentidos coletivos de aprendizagens em Ciências se iniciou nessa pesquisa a partir da busca por uma conscientização freireana (Freire 2017) dos/das estudantes. Assim, coube ao professor indagar: Como se dá a práxis social pelo fazer-ser dos estudantes em autoria tecnocientífica? Qual identidade tecnocientífica se está formando nos/nas estudantes? Relativamente a essas respostas, atentamos, como professores, sobre quais conteúdos poderiam silenciar e/ou (re)afirmar colonialidades do ser e do saber, como assegura o semiólogo argentino Walter Mignolo (2003) apud Maldonado-Torres (2008: 94): “A 'ciência' (conhecimento e sabedoria) não pode ser separada da linguagem; as línguas não são apenas fenômenos 'culturais' em que as pessoas encontram a sua 'identidade'; elas também são o lugar onde se inscreve o conhecimento. E, dado que as línguas não são algo que os seres humanos têm, mas algo que os seres humanos são [...]".

Por essa perspectiva da linguagem, para ensinar Ciências, importa entendermos o lugar em que se inscrevem saberes e conhecimentos de nossos/as estudantes, sua efetiva função social ante as interações que estabelecem com o ambiente, os eventos, os fenômenos, dentro de difusas 
dinâmicas que se dão em experiências coletivas. E, nessa pesquisa, principalmente quanto às interlocuções estudante-comunidade-estudante.

De outra forma, cumpre destacarmos o fenômeno da colonialidade, uma vez que a perspectiva em que pautamos a pesquisa buscou os sentidos coletivizados relativos ao trato dispensado à tecnociência por estudantes em nível de formação escolar básica, tanto pela iniciação científica quanto pela divulgação. Nesse sentido, importa situarmos o fenômeno modernidade/colonialidade no mundo ocidental em que, segundo tese do sociólogo peruano Aníbal Quijano (1928-2018), as sociedades originárias presentes nos ambientes colonizados foram assujeitadas a novas formas-conteúdos de identificação histórica por uma matriz de referência eurocentrada. Marco de produção dos conceitos raça e identidade racial. Dessa forma, regiões e populações das Américas sofreram um processo de re-identificação histórica, dadas as novas referências eurorreferenciadas para o denominado "Novo Mundo", ao tributar-nos excêntricas identidades geoculturais (Quijano 2005). Isso implicou um onto-epistêmico processo de anulação, silenciamento, subalternização e periferização inter-subjetiva de povos e sociedades ancestrais e originárias, inferindo sobremaneira na constituição do ser e do saber, em termos de referencialidades e validades tecnológicas e científicas.

Por essa tese sociológica, entendemos a colonialidade do saber como processo que afeta incisavemente os modos de pesquisar, de ensinar, de aprender, de problematizar, de classificar, sobretudo, de inferir sobre um objeto de estudo nas Ciências. Não nos damos conta das múltiplas e profícuas inter-relações socioculturais, ambientais, ancestrais, míticas, religiosas, ou seja, intersubjetivas que atravessam pensamentos-linguagens por cosmogonias e cosmovisões que poderiam promover outros sentidos de aprendizagem. Ou melhor, estamos impregnados por um saber científico universalista. Fato esse que afeta diretamente o Ensino de Ciências e as condições de produção do saber e do ser dos/as sujeitos/as escolares: sua autoria e sua existência.

Pois, para uma educação em ciências que promova um ambiente autoral, há que se instigar diálogos afirmativos de identidades do ser e do saber dos/das estudantes (Silveira et al. 2018). E, por tais identidades, que entendemos subsumidas colonialmente, é que tentamos fazer emergir sentidos de aprendizagens em Ciências daqueles/as estudantes dentro de um processo de produção editorial. Para tanto, romper com a colonialidade do ser, nessa perspectiva, é promover um ambiente metodológico em plenitude de liberdade de expressão (gênero, sexo, etnia, classe) no âmbito do pensamento-linguagem de cada indivíduo, que se permita em negociação solidária com seus pares. Formulando e constituindo um repertório de linguagens pela via de um processo democraticamente participativo, ontológico, autoral, formativo e pertencente a um discurso CTS comunitário. Logo, privilegiamos o ser-estudante nessa interlocução, pois segundo Fals Borda

\footnotetext{
As atuais tendências homogeneizantes do mundo, que paradoxalmente tendem a criar um ethos de incerteza, convidam a enfrentar estes problemas com inteireza e originalidade, para buscar a reconstrução de outro mundo, conforme uma ordem ética segura ou com a articulação de um ethos alterno, mediante um novo humanismo (Fals Borda 2015: 309 - traduzido pelos autores).
}

Por esse ethos alterno é que pensamos a construção de autorias tecnocientíficas no ambiente escolar, em plena dialogicidade com textos CTS, mobilizando a leitura e a escrita que afirmem identidades socioculturais sobre os modos de ser e de saber desses/dessas estudantes ante objetos, fenômenos, eventos, diversidades, mediados pelo conhecimento tecnocientífico ensinado na escola. Assim, no caso desse projeto, o professor de Ciências e o educando assumem seu papel de sujeitos cognoscentes, mediatizados pelos artigos científicos na área de Física fenômenos físicos em sua realidade comunitária (objeto cognoscível) - que se desafiaram produzir para a revista científica. Entre si, e com os outros, mobilizando o ato de conhecer, imergem em dialogicidade em torno do objeto cognoscível. Isso revela a dimensão gnosiológica contida naquilo que o educando traz no campo de suas percepções, sonhos, pretensões, visão de mundo (Freire 2013).

É por essa dimensão de cognoscibilidade do mundo pelos/as estudantes - e, em 
específico, sobre o objeto de estudo selecionado na escola -, é que se ativa o processo de dialogicidade que entendemos dentro do funcionamento de linguagens na educação em ciências, subentendendo as implicações sociais da ciência e da tecnologia que se reiteram por espaços privilegiados da escola pública (Cassiani et al. 2012).

Na mobilização de componentes pessoais (escolares e comunitários/as) e não-pessoais (parâmetros, diretrizes, bases, concepções, planos, planejamentos e projetos políticos pedagógicos) para o funcionamento de uma efetiva linguagem tecnocientífica, tomamos como aporte o efeito-leitor (Silva 2006; Orlandi 2012) que perpassa toda comunicação científica, afetando sujeitos e sentidos em extensão (Freire 2013), dentro do processo pedagógico. Uma vez que

\footnotetext{
O discurso de divulgação científica não é uma soma de discursos: ciência mais jornalismo igual divulgação científica $(\mathrm{C}+\mathrm{J}=\mathrm{DC})$. Ele é uma articulação específica com efeitos particulares, que se produzem pela injunção a seu modo de circulação, estipulando trajetos para a convivência social com a ciência (Orlandi 2012: 151).
}

Pela injunção de formas-conteúdos na comunicação do conhecimento científico é que se dá a formação de sujeitos-leitores. Estes representados, em interlocução, no texto que, ao comunicar, promove mecanismos de antecipação, inteligindo seus efeitos de sentidos que se constituem no próprio efeito-leitor (imaginário de leitura) (Orlandi 2012).

Pois, é buscando efeitos-leitores que desafiamos a escola básica para a produção de uma revista científica, pela interlocução de autorias tecnocientíficas de estudantes.

Como formação discursiva CTS em aulas de Ciências a entendemos pela via da Educação CTS freireana, promovendo novas formas-conteúdos de abordagem para o ensino de ciências (Von Linsingen 2007; Cassiani \& Von Linsingen 2010; Busko \& De-Carvalho 2019; Jacinski et al. 2019). Atentos ao fato de que na mesma dinâmica em que as instituições produzem e processam a CT, as sociedades tendem a organizar seus espaços formativos para o ensino de ciências por currículos que deem conta de preparar indivíduos para refletirem criticamente sobre essa dinâmica.

Ressaltamos, também, outros tensionamentos discursivos que devem ser levados para aulas de Ciências, ao tratar de questões de natureza étnica e de gênero dadas as múltiplas relações de poder no ambiente de produção da ciência e da tecnologia; praticar pedagogias CTS críticas que se aproximem de uma concepção educacional freireana; perceber discursos que fazem circular a ciência e a tecnologia como entes de construção e de circulação de sentidos; bem como desenvolver um trabalho escolar na dimensão das pedagogias decoloniais, valorando saberes e culturas locais, linguagens de povos originários (indígenas e quilombolas), ou seja, aproximando-se com as epistemologias do Sul (Von Linsingen \& Cassiani 2013 apud Oliveira \& Von Linsingen 2019).

\section{Movimento CTS no Ensino de Ciências}

O século XXI é cenário de intensos fenômenos de globalização mundial em todos os setores socioculturais, econômicos, educacionais, tecnocientíficos e políticos, produzindo formas e conteúdos mais profundos e reflexivos de intervenção na escola básica.

Também se tornou o século com maior recorrência sobre as tratativas do termo CTS em associação com perspectivas e sentidos gerados por sociedades periferizadas pelo capitalismo, que têm reclamado: pautas de direitos humanos, equidade/justiça étnico-racial, ensino situado de ciências, responsabilidade socioambiental, formação de cidadanias plurais, discussões sobre democracia participativa, protagonismo de saberes de pessoas subalternizadas e excluídas (Von Linsingen 2007), intencionalidades de inserção e transferência de tecnologias provindas de países centrais, às 'tecnologias sociais / tecnociência solidária' (Dagnino 2019). Enfim, tensionam importantes discussões e narrativas carreadas desde meados do século XX (a partir de 1960; cf. Galieta \& Von Linsingen 2019) quando se tratou de revisionar paradigmas latino-americanos 
que até então estavam consolidados pelos centros hegemônicos sobre suas ex-colônias.

Por esses sentidos, alia-se o Pensamento Latino-Americano em Ciência, Tecnologia e Sociedade (PLACTS) que surge nos anos 1970, com Dagnino, Thomas e Davyt (1996) apud Dagnino (ibidem), propondo-se a repensar estratégias sobre a dependência, o subdesenvolvimento e a desigualdade das ex-colônias, e as novas reflexões sobre CT, acirrando o chamado movimento CTS.

Na educação, esse movimento vem sendo foco privilegiado de diversos campos e áreas do conhecimento, através do Estudos Sociais da Ciência e Tecnologia (ECTS), aproximando questões problemáticas sobre a produção e a concepção de CT, como podemos ver em Von Linsingen (2007), Cassiani \& Von Linsingen (2010), Galieta \& Von Linsingen (2019) e Oliveira \& Von Linsingen (2019).

Dessa forma, afeta-nos a formação discursiva na Educação Básica, ambiente em que temos desenvolvido nossos estudos e pesquisas, sob a compreensão metodológica dessas interseccionalidades, uma vez "não podermos mais ignorar o padrão global basilar e administrador de todas as opressões" [...] "onde estejam as populações de cor acidentadas pela modernidade colonialista até a encruzilhada, buscar alimento analítico para a fome histórica de justiça." (Akotirene 2019: 23).

Sentidos em que pensamos o movimento, do lado de cá, como ruptura e resistência de opressões históricas a que o currículo é submetido na escola básica, para decolonizá-lo (Quijano 2005; Mato 2014). Por isso, importa-nos também destacar que as políticas educacionais STEM norte-americanas, ou seja, que promovem escolhas curriculares sob o viés da 'competitividade', da 'performance' dos estudantes, coadunando ciência, tecnologia, engenharia e matemática (cujas iniciais em língua inglesa formam a sigla) - e que em certa medida se acopla a Base Nacional Comum Curricular (BNCC), no Brasil - não promovem o diálogo que pretendemos com esse projeto, uma vez que as ciências naturais (Física, Química e Biologia) na Educação Básica são pretendidas a partir de problemas locais, autóctones, partilhados e negociados comunitariamente. Nesse sentido, é que privilegiamos a Educação CTS freireana (Cassiani \& Von Linsingen 2010) e latino-americana, a partir da qual temos compreendido interesses pluriversais e pluridentitários de outros movimentos, com pautas: feministas, de negritudes, indígenas, GLBTQIA+ (gêneros e sexualidades contranormativas), de imigrantes, de anistiados, de refugiados, ou seja, por discursos e práxis pedagógicos interseccionais no Sul global.

\section{Metodologia de investigação-ação-participativa (IAP)}

No ano de 2015, mobilizamos uma escola da rede pública de ensino em Florianópolis, capital de Santa Catarina, para a elaboração de uma revista científica com estudantes do Ensino Fundamental. Esse grupo de estudantes foi formado por livre manifestação de interesse de 10 estudantes, dentre os/as 136 regularmente matriculados/as no $9^{\circ}$ ano daquela escola. A chamada para o trabalho de produção editorial da revista foi feito em forma de convite aberto, realizado em 5 reuniões de apresentação da proposta a cada turma de trabalho do Professor de Ciências. Aos/às estudantes foram apresentados: os objetivos do projeto de produção da revista; seu vínculo com os projetos de ciências em curso (realizados em aulas de ciências como parte da metodologia docente daquela escola); o cronograma de trabalho (em contraturno, um dia por semana); e o produto final da revista. Em todas as reuniões, o Professor de Ciências (um dos autores deste texto) deixou claras as intenções finais para uma produção de pesquisa estritamente acadêmica.

Dentre 5 turmas de $9^{\circ}$ ano daquela escola, as mesmas se subdividiam em dois períodos de oferta, sendo três turmas no matutino e duas no vespertino. Dessa forma, quando a reunião era realizada no período matutino, quatro estudantes garantiam comparecimento no contraturno de aulas; e, quando no período vespertino, seis compareciam. Logo, seguimos com a ideia de alternância entre os períodos matutino e vespertino, a cada semana, para não comprometer a participação de qualquer dos/as integrantes. Foram realizadas no total 8 reuniões entre o grupo editorial, no período de 12 de agosto a 30 de setembro de 2015, ou seja, no $3^{\circ}$ 
bimestre daquele ano letivo.

As reuniões seguiam uma pauta prévia e elaborada na semana anterior, sobre pontos que ficavam em aberto. Em nenhum momento surgiu a ideia de elaborar uma ata para registro das discussões. Os estudantes observavam que o professor registrava por escrito (em um diário de bordo) tudo o que transcorria. Com isso, pediam ao professor que lesse o que havia sido registrado na reunião anterior, mesmo assim não tomaram a iniciativa de um registro por escrito. Isso demonstrou a inexperiência natural do coletivo em formatos de atividade extraclasse. Importante ressaltar que o professor, mesmo como observador participante e registrador, não interferia em qualquer decisão quanto a definição de pautas, temas de artigos, organização, artes e formatos, evitando o modelo tecnocrático. Sua função era a de fazer mediações junto à direção escolar para viabilidade do projeto. Além de mostrar caminhos de busca e pesquisa, critérios de qualificação dos textos (como por exemplo a sugestão de buscas e referentes no Caderno Brasileiro de Ensino de Física e na Revista Brasileira de Ensino de Física).

A práxis docente que articula aspectos da realidade em interlocução com o conhecimento tecnocientífico ensinado na escola é capaz promover uma reelaboração discursiva por significativas apreensões e construções de outros conhecimentos, cumprindo uma importante função social no ensino de ciências: a formação discursiva.

\begin{abstract}
Se queremos que na escola se formem leitores-autores é fundamental que os professores sejam levados a refletir sobre tais questões. Quando se trata de conhecimento científico essa ausência de discussões e problematizações sobre a linguagem pode trazer diversas conseqüências indesejáveis para a aprendizagem, uma delas está em interpretar a ciência como conhecimento único, inquestionável, infalível, pronto, ou seja, tem como conseqüência o desenvolvimento de visões de ciência neutra, objetiva, que retrata fielmente a realidade e que independe das relações sociais estabelecidas (Giraldi 2010: 70).
\end{abstract}

Por essa perspectiva de trabalho das ciências, como um processo eminentemente humano, envolto em relações de poder, de escolhas e de decisões no âmbito de coletividades políticas e socioculturais, foi que o projeto de uma revista se inseriu: a construção de sentidos coletivos sobre discursos CTS na comunidade escolar.

Para maior conhecimento da equipe de 10 estudantes, aplicamos um questionário para entender algumas regularidades de pensamento, linguagem e identificação com a CT, quanto a aspectos relacionados a: hábitos de leitura e escrita; tipos de literatura escolhida; afinidades com textos científicos; entender a importância para a divulgação científica às comunidades; infraestrutura para produção de textos; disponibilidade de horários; motivação para a pesquisa, dentre outros (ver Quadros 1 e 2).

O trabalho compreendeu a metodologia de investigação-ação-participativa (IAP), do sociólogo colombiano Orlando Fals Borda (1925-2008), uma vez que “é central a crença de que cada pessoa e comunidade possui um conhecimento próprio que deve ser considerado como elemento-chave no desenho de qualquer projeto de pesquisa ou trabalho político.” E, assim, “(...) a articulação entre saberes de especialistas e saberes locais resulta em uma sinergia produtiva." (apud Mato 2014: 258; traduzido pelos autores). Por saberes locais de 10 estudantes, no tempo de 8 reuniões metodológicas (cf. Quadro 3), procedeu-se o pleno diálogo de saberes contido no ouvir, no olhar e no falar desses/as estudantes.

\footnotetext{
A IAP é, a um só tempo, um método de investigação, uma técnica educativa e uma ação política. Não é somente investigar, nem somente educar, nem somente atuar. É uma tríade permeada por uma filosofia de vida, que a satura como um todo e com a qual se poderia reconstruir a sociedade como uma força nova. A IAP é, desse modo, uma metodologia dentro de um processo vivencial (Fals Borda \& Zamosc 1985 apud Mota Neto 2018: 6).
}

A concepção falsbordiana propõe dentro da dinâmica social em IAP que os coletivos de sujeitos/as subalternizados/as mobilizem a seu modo de ser, de saber e de viver o processo de 
seleção do problema, sua resolução e posterior popularização, através da apresentação/retorno dos resultados da pesquisa com o/ao meio social, coletivizando-os (Renaud \& Sánchez 2015). Ou seja, que a busca de soluções para o problema comunitário seja capaz de tornar a "investigação um procedimento dialógico e conscientizador." (Mota Neto ibid.: 12).

Para tanto, entendemos um ciclo em cada fase da IAP no Ensino de Ciências - que ciclam entre si -, a saber:

Fase de investigação - fase inicial por sua importância na busca "de temas geradores no contexto do ensino de ciências, promovendo formações discursivas que deflagram a realidade dos/as educandos/as e nas quais se ressignificam sensos, saberes e conhecimentos socioambientais historicamente produzidos." (Busko \& De-Carvalho 2019: 11). Essa é a fase da busca temática propriamente dita, da pergunta aderida à intencionalidade de saber.

Fase de Ação - momento no qual "mobiliza-se o pensamento com a ação, numa perspectiva dialética sobre a realidade a ser transformada no seio da escola, mas principalmente pelas aprendizagens em ciências.” (Busko \& De-Carvalho ibidem). Essa realidade a ser transformada parte da dialogicidade sobre o objeto cognoscente no seio da escola, mediada pelo intelectual orgânico, reconhecido pesquisador, o Professor de Ciências que faz a mediação entre o método-conteúdo e objetivo-avaliação para o tema a ser investigado, valorando o ser-estudante que entrará em ação. Gestos, culturas, identidades, ritmos, verdades, sentidos de mundo, produzirão o repertório de linguagens para a subjetividade contida em seu acionar.

Fase de Participação Social - que

constituiu um dos principais aportes da IAP à educação popular, o que reforçaria a sua busca originária de superar a relação verticalizada entre sujeito (professor) e objeto (aluno). Para o sociólogo, a essa dimensão dialógica interpessoal somam-se outras contribuições: epistemológica, pela afirmação do diálogo de saberes; institucional, pela necessidade de construção de universidades ou escolas participativas; e paradigmática, pelo estímulo à constituição de novos modos de conceber a realidade e produzir conhecimento (Mota Neto op. cit:: 8).

Ressaltamos como importante objetivo da metodologia falsbordiana, sendo:

[...] para alcançar melhores e maiores níveis de conhecimento científico, assim como de conhecimento prático a fim de resolver situações e/ou problemas concretos, e criar 'contra-poderes', é conveniente reconhecer as limitações de todos os atores na experiência investigativa (Fals Borda 2015: 324 - traduzido pelos autores).

Bem como estratégicos direcionamentos em seu desenvolvimento, a saber:

O rigor investigativo não se julga somente por medições quantitativas, ainda que estas possam ser necessárias na descrição e explicação dos resultados do trabalho. As medições devem incrementar-se com descrições qualitativas pertinentes, que são igualmente válidas e necessárias (ibid: 327; ênfase do original; traduzido pelos autores).

A avaliação de resultados não se executa necessariamente ao término de um período dado ou pré-fixado pelo conhecido ritmo de reflexão-ação, como se fosse um procedimento bancário unilinear, ou unicasual em mãos de planejadores, senão que pode dar-se ao compasso do trabalho de campo, como estímulos à ação (ibid.: 328; ênfase do original; traduzido pelos autores).

Tanto em termos de objetivo epistemológico quanto nos direcionamentos da metodologia, Fals Borda (ibid.) deixa clara sua perspectiva sociológica no sentido em que entende o processo de continuidade como fuga a procedimentos bancários, passivos, lineares, ou de imposição de regras e critérios. Propõe a dissipação de tendências hegemônicas, aqui tomadas no âmbito escolar como os processos de avaliação performática e quantitativa.

Chamamos atenção para o fato que as referidas fases não se hierarquizam entre si, mas 
ciclam dialeticamente em torno do pensamento-linguagem que marca a identidade do ser coletivo.

Os relatos/depoimentos dos estudantes foram motivados pelo Professor de Ciências, ao final dos trabalhos da comissão editorial, orientando-lhes a expressarem por escrito até que ponto supriram suas expectativas, os aspectos que precisariam de maior atenção em um projeto futuro, suas limitações e desafios. Para tanto, foi-lhes solicitado que não se identificassem, para que se sentissem o mais livres possível ao produzirem suas narrativas.

Toda a apreensão de dados desta pesquisa foi feita em conformidade com o que estabelecem as resoluções sobre ética sob controle da Comissão Nacional de Ética em Pesquisa CONEP, junto ao Conselho Nacional de Saúde, órgão do Ministério da Saúde, principalmente atentos à resolução 466/2012/CNS, relativa à pesquisa envolvendo seres humanos. Extensivamente, embora editada em 2016, cumprimos seguramente à Resolução 510/2016/CNS, com o pleno esclarecimento e comunicação dos/das gestores/as escolares e do Professor de Ciências junto à Associação de Pais e Professores (APP), daquele espaço escolar, expondo-lhes a livre opção de participação no projeto. Como também, o deferimento do projeto e do plano de trabalho para sua execução, tendo sido os mesmos foram protocolados junto ao órgão de controle/regulação de atividades de pesquisa acadêmica da Secretaria Municipal de Educação, na cidade de Florianópolis, Santa Catarina. Os resultados finais foram depositados junto ao referido órgão.

\section{Processo pedagógico formador de discursos CTS}

Inicialmente, constatamos que os sentimentos de pertença ao grupo se manifestaram pelo tempo relativo que os estudantes destinavam à leitura-escrita, ao registrarmos que $80 \%$ (8) dos participantes dedicavam entre 8 e mais horas semanais para essa atividade. "Quando se trata dos estudantes do ensino fundamental, esse resgate é extremamente importante, pois essas reflexões produzem efeitos de sentidos de como o estudante se vê como leitor e como essa história pode se modificar.” (Cassiani et al. 2012: 50). E, voltando-nos para as áreas do conhecimento que mais lhes instigavam à maior dedicação de tempo, temos: Língua Portuguesa (40\%), seguida das Ciências (30\%) (Quadro 1). Resultados que revelaram pertença e afinidade com o grupo, para o desafio da produção editorial da revista científica.

Quadro 1. Dados levantados dos questionários para pesquisa de interesse.

\begin{tabular}{|c|c|c|}
\hline \multicolumn{2}{|c|}{ Na semana, em média, quanto tempo você passa lendo e escrevendo? } & $\begin{array}{l}2 \text { horas semanais: } 2(20 \%) \\
8 \text { horas semanais: } 4(40 \%) \\
+10 \text { horas semanais: } 4(40 \%)\end{array}$ \\
\hline Qual o último livro que você leu? & $\begin{array}{l}\text { Convergente } \\
\text { Percy Jackson e os olimpianos } \\
\text { A culpa é das estrelas } \\
\text { Jogos vorazes 3: a esperança }\end{array}$ & $\begin{array}{l}1(10 \%) \\
3(30 \%) \\
2(20 \%) \\
4(40 \%)\end{array}$ \\
\hline Qual o livro que você mais gostou de ler? & $\begin{array}{l}\text { Série: Percy Jackson } \\
\text { A culpa é das estrelas } \\
\text { Livros de Jogos Vorazes } \\
\text { Saga de Harry Potter }\end{array}$ & $\begin{array}{l}4(40 \%) \\
1(10 \%) \\
3(30 \%) \\
2(20 \%)\end{array}$ \\
\hline $\begin{array}{l}\text { Em quais disciplinas você se sente mais } \\
\text { desafiado a estudar? }\end{array}$ & $\begin{array}{l}\text { Língua Portuguesa } \\
\text { Ciências } \\
\text { Matemática } \\
\text { História }\end{array}$ & $\begin{array}{l}4(40 \%) \\
3(30 \%) \\
2(20 \%) \\
1(10 \%)\end{array}$ \\
\hline
\end{tabular}

Os resultados do Quadro 1 revelam importantes questionamentos que devem estar em discussão no planejamento no ensino de ciências no que se refere à formação leitora, tanto de professores de Ciências quanto de estudantes. E, isso infere sob a formação discursiva no território da escola pública. Vejamos as questões: 
- de que forma as histórias de leituras dos estudantes e professores influenciam em sua constituição enquanto leitores?

- como os estudantes e professores se percebem enquanto leitores?

- que sentidos os estudantes estabelecem para a linguagem nas ciências e sua leitura?

- $\quad$ será possível intervir nas histórias dos estudantes? (Cassiani et al. ibidem)

Buscar tais respostas pela via da dialogicidade freireana foi seguramente o que empreendemos pela metodologia IAP. A formação de sujeitos-leitores e mobilizadores de discursos CTS passou pela linguagem, pela literatura, pelos pensamentos ante as relações de CT no cotidiano comunitário dos/as estudantes. Isso promoveu um processo de intervenção qualitativa para a assunção de posturas mais críticas, democraticamente participativas, e principalmente estruturado em trajetos pedagógicos possíveis para uma efetiva inclusão de diversidade cidadã. E, isso é um passo para efetivas práticas decoloniais para a formação do ser e do saber tecnocientíco. Sujeitos e efeitos-leitores decoloniais de ciências.

Isso reflete a unanimidade $(100 \% ; 10)$ do grupo editorial quanto aos seguintes aspectos de autopercepção, vez em que os/estudantes: consideram-se estudantes-pesquisadores; compreendem a divulgação científica como forma de educar as sociedades; refletem sobre os métodos de trabalho das Ciências para a produção de conhecimentos; têm interesse/curiosidade por temas de Ciências; possuem habilidade em editar textos, conforme apresentamos no Quadro 2.

Quadro 2. Outros dados levantados na pesquisa de interesse.

\begin{tabular}{|c|c|c|}
\hline & Sim & Não \\
\hline Você tem o costume de escrever histórias, contos ou poesia? & $8(80 \%)$ & $2(20 \%)$ \\
\hline Possui tempo e espaço para ler e escrever? & $10(100 \%)$ & 0 \\
\hline $\begin{array}{l}\text { Você considera que a divulgação de informações científicas é importante para educar a } \\
\text { sociedade? }\end{array}$ & $10(100 \%)$ & 0 \\
\hline $\begin{array}{l}\text { Você acredita ser capaz de produzir novos textos científicos com seu processo de leitura e } \\
\text { interpretação de novidades, notícias, informes, e divulgações em geral das Ciências? }\end{array}$ & $9(90 \%)$ & $1(10 \%)$ \\
\hline Você considera que seu modo de produzir textos ajudará na produção de textos científicos? & $8(80 \%)$ & $2(20 \%)$ \\
\hline Você se considera um estudante-pesquisador/a? & $10(100 \%)$ & 0 \\
\hline Você pensa no método como as ciências desenvolvem e produzem conhecimento? & $10(100 \%)$ & 0 \\
\hline Você segue algum método para produzir, estudar e/ou criar seus conhecimentos? & $4(40 \%)$ & $6(60 \%)$ \\
\hline Você tem curiosidade e interesse por assuntos e temas das Ciências? & $10(100 \%)$ & 0 \\
\hline Tem computador em casa? & $10(100 \%)$ & 0 \\
\hline Possui acesso à internet em casa? & $8(80 \%)$ & $2(20 \%)$ \\
\hline $\begin{array}{l}\text { Você tem Smartphone? E utiliza aplicativos de trocas de mensagens (WhatsApp, WeChat, IMO, } \\
\text { etc.) }\end{array}$ & $7(70 \%)$ & $3(30 \%)$ \\
\hline Sabe utilizar programa de editor de textos? & $10(100 \%)$ & 0 \\
\hline Possui disponibilidade para comparecer na escola nas quartas-feiras no contraturno? & $10(100 \%)$ & 0 \\
\hline $\begin{array}{l}\text { Possui disponibilidade de ir a uma saída de estudo ao bairro Centro, acompanhado do } \\
\text { professor? }\end{array}$ & $7(70 \%)$ & $3(30 \%)$ \\
\hline
\end{tabular}

Neste ponto de análise, ressaltamos particularmente a pergunta: Você considera que a divulgação de informações científicas é importante para educar a sociedade?, que obteve unanimidade de respostas 'sim', ou seja, ao considerarem a importância de democratização (circulação) do conhecimento científico para todos/as. Complementamos essa análise com uma 
pesquisa de Auler et al. (2005), em que os respondentes defendiam uma "Postulação de algo próximo da democratização das decisões em temas que envolvem Ciência-Tecnologia” (8). A maioria dos respondentes daquela pesquisa assinalou o seguinte: "Representantes de vários segmentos da sociedade, o que inclui a comunidade científica” (ibidem), quanto a um parâmetro estipulado de: "Superação do Modelo de Decisões Tecnocráticas” (ibidem). Isso gerou nos/as pesquisadores/as o entendimento de que os respondentes eram favoráveis em envolver a sociedade em questões de litígio científico e tecnológico, que, no caso particular daquela pesquisa, propunha entre tomada de decisões tecnocráticas (cientistas decidindo), em menor número de adesões, e a defesa da democratização das decisões envolvendo assuntos de CT, com maior número de adesões.

Entendemos, com isso, que nossos/as estudantes defendem interlocuções entre sociedade e comunidade científica, pela democratização do conhecimento. Fato é que, ao ocuparem a posição de mediadores do conhecimento científico, sujeitos em estado mais cognoscente (que seus pares) sobre a temática do projeto, compreendem que o alcance da CT na sociedade precisa ser comunicado pedagogicamente. Ou melhor, os estudantes se inscrevem em um imaginário de leitura que promove o mecanismo de antecipação de um fato tecnocientífico para um acontecimento social. E, isso produz sentidos críticos e aplicados àquela realidade que é politicamente constituída e formulada no discurso CTS

Nas questões que tratam sobre método e problemas das Ciências, sendo: Você pensa no método como as ciências desenvolvem e produzem conhecimento? Você segue algum método para produzir, estudar e/ou criar seus conhecimentos? Você tem curiosidade e interesse por assuntos e temas das Ciências?, as compreendemos quanto aos sentidos que o conhecimento científico institucionalizado (escola, agências, universidades, institutos), divulgado na mídia, gerador de discussões, é acreditado pelos/as estudantes tanto pela importância de seu produto quanto por seu processo de trabalho. De outra forma, os conhecimentos que os/as mesmos/as produzem não cumprem $(60 \% ; 6)$ o método e o rigor que têm as Ciências, o que atesta os referidos efeitos de colonialidade do saber sobre a validez do que é ou não científico. E, isso é um alerta, pois mesmo assumindo-se na posição de estudantes-pesquisadores/as (100\%; 10), a escola precisa garantir que os efeitos e os sentidos de suas aprendizagens chancelem intencionalidades, abordagens e enfoques sobre formas-conteúdos ensinados. Relativamente à identidade que permeia seu método pessoal de compreender, de organizar seu tempo, de focar seu pensamento, de se comunicar, de responder, de se relacionar, de fazer escolhas, ou seja, implicando sobre suas respostas maior ou menor afetação quanto às questões tecnocientíficas.

Importante refletirmos sobre a categoria da intencionalidade dos sujeitos ao fazerem ciência, ao divulgarem seus resultados, ao promoverem a democratização da tecnologia por seu viés ideológico. As intencionalidades, quer sejam pedagógicas/de ensino (do intelectual orgânico), quer sejam de aprendizagens (do sujeito-leitor), formulam o ambiente do p.p.p. e constituem interconexões de sentidos CTS para o que vivem, sentem e gestualizam esses sujeitos. Ou seja, comportam nessa categoria as formas-conteúdos quanto ao que avaliar, planejar, dar respostas, solucionar. E, isso muito nos importa quando pensamos na formação de uma massa crítica para as futuras gerações de cientistas política e humanamente situados quanto à alteridade do trabalho e do produto da ciência e da tecnologia que produzirão.

Em outro contexto, Auler (2007), ao explicar sobre a pedagogia freireana, situa tensões entre o que chama de 'mundo da escola' (entendemos o mesmo sob as formalidades da gestão de seu processo pedagógico: componentes pessoais e não-pessoais) e o 'mundo da vida' (o cotidiano do/a estudante, seus conflitos, interesses, escolhas, gestos, comportamentos, ideias e ideais) que, via de regra, ambos não entram em interlocução no modelo de escola hegemônica. Concordamos com esse autor, ao situar que, para Freire, há uma possibilidade de imbricar tais mundos através de temas geradores, pois esses são capazes de carregar "para dentro da escola a cultura, as situações problemáticas vividas, os desafios enfrentados pela comunidade local. $\mathrm{O}$ mundo vivido, os problemas e as contradições nele presentes passam a ser o ponto de partida.” (Auler ibid.: 5) Essa interlocução o define como tema que gera importâncias/protagonismos de sujeitos/as dentro da conjuntura do real, estimulando esses como sujeitos-leitores na busca de 
respostas autorais para seus problemas reais.

O Quadro 2 teve a função de operar como um marcador de perfil sobre as movimentações dos estudantes no meio sociotécnico, a fim de que pudéssemos pensar criticamente o espaço da escola, ao seguirmos adiante na implementação do projeto, bem como promover uma ruptura com ensinamentos de conteúdos e proposições de materiais didáticos que parecem acabados e estáveis no currículo, mascarando a perenidade do fazer científico e tecnológico.

De um lado persistem formas tecnocráticas de construir relações desprovidas de participação pública no processo de modernização ou ainda desconsiderando a riqueza dos saberes tradicionais e das culturas locais para a solução dos nossos problemas. Exemplos dessas configurações são muito enfáticos nas áreas da educação bancária, como já enfatizava Paulo Freire, política de saúde pública que desconsidera saberes populares, agricultura voltada para interesses do agronegócio, mobilidade urbana desconsiderando realidades geográficas e culturais locais, política da informação e comunicação antidialógica, etc. (Jacinski et al. 2019: 195)

Com isso, entendemos que a mobilização temática pela IAP criou esse espaço de interlocução entre o mundo tecnocientífico, o mundo sociocultural e o mundo da escola. Espaço esse permeado por constantes processos de comunicação pedagógica inventivamente elaborado pela comissão editorial, tanto por gestos particulares/subjetivos quanto pela sinergia do senso coletivo de produção de uma escrita/leitura tecnocientífica que alcançasse as comunidades. E, pelo próprio retorno que se deu na interlocução com essas comunidades.

Dessa forma, passamos ao processo de produção autoral, conforme descrito no Quadro 3 que segue.

Cada etapa de avaliação era definida em coletivo, baseando-se na reunião anterior. O quórum de $100 \%$ (10) de participação em 4, de $90 \%$ (9) em 2 e de $80 \%$ (8) em 2 , do total de 8 reuniões realizadas, demonstra a efetividade na escolha metodológica, para uma situação que se propôs como extensiva e investigativa no campo da Educação em Ciências. O nível de comprometimento e motivação para o trabalho editorial foi tamanho que, mesmo aqueles/as estudantes que teriam reunião somente no contraturno em outra semana, compareciam nos intervalos de seu turno de estudos para acompanhar as discussões e tomar decisões coletivas, por livre e espontânea vontade em estarem reunidos/as para o projeto.

Educar para coletividades autogestionadas, para autonomia e alteridade na compreensão de fenômenos produtivos e processos tecnocientíficos, ou melhor, educar para uma postura de democracia participativa e decisória. A autoria emergiu como um ponto de inflexão do ser (modos, gestos, discursos, falas, ideais, inter-relações) e do saber (seleções do concreto conteúdo tecnocientífico que atende sua comunidade por suas escrituras e leituras) dos/das estudantes quanto aos discursos CTS.

Ressaltamos como importante pauta das reuniões, o ocorrido em 19 de agosto de 2015, quanto à decisão da forma de liderança do grupo. As mesmas eram organizadas e mediadas sempre por um/a estudante diferente da semana anterior, por livre decisão e disponibilidade pessoal. Isso partiu do próprio grupo, sendo questionada a necessidade de uma estrutura mais formal com presidente e demais membros, no entanto decidiram por não haver poder centralizado. Decisão que demonstrou a busca por maturidade e compartilhada responsabilidade.

A autoria tecnocientífica é afetada no discurso em sensos pesssoais, bem como em consensos e dissensos pelas inter-relações socioculturais, dado o devir no projeto de fazer-ser social de cada estudante que se constitui e formula

\footnotetext{
Por concepções e relações de trabalho; por expressões, impressões e compreensões étnico-raciais, de gênero/sexualidade; por sensos e saberes de espaço-tempo; por referentes linguísticos; por signos tecnocientíficos; pela ética/estética social; pela organização e relações de poder sociocultural, histórico e político-econômico; por sentidos particulares de mundo: ancestralidades, transcedências religiosas (De-Carvalho 2019: 179).
} 
Quadro 3. Processo de trabalho de produção editorial dos/das estudantes.

\begin{tabular}{|c|c|c|}
\hline $\begin{array}{l}\text { Data de realização, hora } \\
\text { (tempo utilizado) }\end{array}$ & $\begin{array}{c}\text { Objetivo/Avaliação } \\
\text { (Participantes presentes) }\end{array}$ & Método/conteúdo \\
\hline 12 ago. 2015 , às 9 h30min $(45 \mathrm{~min})$ & 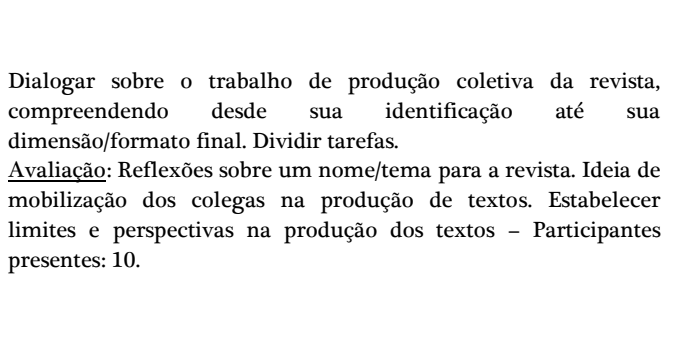 & $\begin{array}{l}\text { Apresentação espontânea de cada } \\
\text { participante. Objetivo de participação } \\
\text { no trabalho editorial. Consensos } \\
\text { coletivos sobre o caráter da pesquisa } \\
\text { no âmbito da comunidade escolar. } \\
\text { Diálogo de saberes e expectativas dos } \\
\text { estudantes sobre a produção da } \\
\text { revista, e sua temática. Divisão de } \\
\text { tarefas. Formato de textos para } \\
\text { recepção: tamanho, normalização, } \\
\text { correção. }\end{array}$ \\
\hline 19 ago. 2015 , às $13 \mathrm{~h} 45 \mathrm{~min}(45 \mathrm{~min})$ & $\begin{array}{l}\text { Compor um staff diretivo, entre os pares. Definir o tamanho da } \\
\text { revista, conforme o número de textos recepcionados. } \\
\text { Avaliação: Decisão de não hierarquizar o trabalho. Definição de } \\
\text { um modelo para a recepção de textos. Estabelecer uma } \\
\text { "qualidade científica" para os textos. A temática dos textos dariam } \\
\text { seguimento ao conteúdo do } 3^{\circ} \text { trimestre letivo: cinemática e } \\
\text { dinâmica. Participação do grande grupo escolar na definição do } \\
\text { nome da revista, relativamente a cada turma que continha seu } \\
\text { representante no corpo editorial - Participantes presentes: } 9 \text {. }\end{array}$ & $\begin{array}{l}\text { Livre discussão sobre hierarquia e } \\
\text { liderança, entre pares. Sobre eleição } \\
\text { de diretoria. Quantidade de textos que } \\
\text { seriam recepcionados por membro. } \\
\text { Definição do nome da revista. }\end{array}$ \\
\hline 26 ago. 2015 , às $9 \mathrm{~h} 30 \mathrm{~min}(45 \mathrm{~min})$ & $\begin{array}{l}\text { Apresentar modelos de textos (artigos), para recepção. } \\
\text { Avaliação: Elaboração de um modelo próprio para a recepção de } \\
\text { textos. Decisão de repasse do modelo às turmas representadas no } \\
\text { grupo. Prorrogação do prazo para definição do nome da revista - } \\
\text { Participantes presentes: } 8 \text {. }\end{array}$ & $\begin{array}{l}\text { Modelos de artigos capturados na } \\
\text { internet. Normas e padronização para } \\
\text { revista de divulgação. }\end{array}$ \\
\hline 2 set. 2015 , às $13 \mathrm{~h} 45 \mathrm{~min}(45 \mathrm{~min})$ & $\begin{array}{l}\text { Discutir sobre a percepção/sugestões da escola sobre a } \\
\text { modelagem dos textos para recepção. Definir o nome da revista. } \\
\text { Avaliação: Aceitação do modelo discutido pelas turmas. } \\
\text { Orientação para a produção de textos dentro do modelo. } \\
\text { Multiplicação pedagógica do modelo aos interessados, em sala } \\
\text { informatizada. Indefinição do nome da revista, pela apresentação } \\
\text { de muitas possibilidades. Importância de uma apresentação } \\
\text { introdutória da revista (editorial) - Participantes presentes: } 10 \text {. }\end{array}$ & $\begin{array}{l}\text { Formas de socialização do modelo } \\
\text { para as turmas. Trabalho orientado } \\
\text { para a adequação/orientação ao } \\
\text { modelo discutido. }\end{array}$ \\
\hline 9 set. 2015 , às $9 \mathrm{~h} 30 \mathrm{~min}$ (45min) & $\begin{array}{l}\text { Definir, por turma/dupla, coletiva e democraticamente (por voto) } \\
\text { o nome oficial da revista. } \\
\text { Avaliação: Apresentação do editorial elaborado, votado, sem } \\
\text { ressalvas entre os pares. Votação entre } 2 \text { nomes sugeridos: } \\
\text { "Cientizando na escola" e "Ciência e educação", elegendo-se o } \\
\text { primeiro. Discussão sobre a baixa qualidade apresentada, } \\
\text { conforme os critérios estipulados. Registro de critérios para os } \\
\text { textos, sendo: a) plagiado; b) fora dos padrões; c) fora do tema. Ou } \\
\text { seja, seguindo uma "avaliação por rubricas" - Participantes } \\
\text { presentes: } 9 \text {. }\end{array}$ & $\begin{array}{l}\text { Elaboração compartilhada de texto } \\
\text { editorial. Nome da revista de } \\
\text { divulgação, conforme objetivo } \\
\text { temático. }\end{array}$ \\
\hline 16 set. 2015 , às $13 \mathrm{~h} 45 \mathrm{~min}(45 \mathrm{~min})$ & $\begin{array}{l}\text { Fazer a seleção, em definitivo, dos textos para compor a revista. } \\
\text { Avaliação: Seleção de } 8 \text { dentre } 11 \text { textos apresentados pelo grupo } \\
\text { (um membro trouxe } 2 \text { artigos como proposta). Discussão sobre a } \\
\text { importância dos artigos selecionados para compor a revista. } \\
\text { Apresentação de uma planilha, ao professor, sobre aqueles artigos } \\
\text { que foram "recusados". Critério de subjetividade na seleção - } \\
\text { Participantes presentes: } 10 \text {. }\end{array}$ & $\begin{array}{l}\text { Importância do tema/conteúdo dos } \\
\text { textos apresentados para composição } \\
\text { da revista. Critérios de } \\
\text { definição/seleção dos textos. }\end{array}$ \\
\hline $\begin{array}{l}23 \text { set. } 2015 \text {, às } 9 \mathrm{~h} 30 \mathrm{~min}(90 \mathrm{~min}) \\
\text { (sala informatizada da escola) }\end{array}$ & $\begin{array}{l}\text { Socializar ideias de revistas em Ensino de Física, bem como um } \\
\text { software livre e aberto para editoração da revista. Gerar o formato } \\
\text { final da revista. } \\
\text { Avaliação: Navegação pelas revistas: Caderno Brasileiro de } \\
\text { Ensino de Física (CBEF) e a Revista Brasileira de Ensino de Física } \\
\text { (RBEF). Manipulação e alimentação do software Scribus, para } \\
\text { edição final dos artigos. Uso do Flickr, com licenças de Creative } \\
\text { Commons. Formatação foi finalizada por cada membro do grupo } \\
\text { - Participantes presentes: } 10 \text {. }\end{array}$ & $\begin{array}{l}\text { Modelos de revistas científicas na área } \\
\text { de Física. Editoração de textos, por } \\
\text { software livre. Regras de uso autoral } \\
\text { de imagens. }\end{array}$ \\
\hline $\begin{array}{l}30 \text { set. } 2015,13 \mathrm{~h} 45 \mathrm{~min} \text { (90min) } \\
\text { (sala informatizada da escola) }\end{array}$ & $\begin{array}{l}\text { Reler toda a produção. Formatar e compilar os textos para um só } \\
\text { arquivo. } \\
\text { Avaliação: Revisão geral de todo o (con)texto. Trabalho coletivo } \\
\text { com projetor multimídia. Planejamento da divulgação na escola, } \\
\text { a partir do evento Festa da Família, realizada em } 3 \text { out. } 2015 \text {. } \\
\text { Disponibilização de cópias para o público - Participantes } \\
\text { presentes: } 8 \text {. }\end{array}$ & $\begin{array}{l}\text { Formato final do texto científico, para } \\
\text { publicação. Conversão de arquivos } \\
\text { para PDF (formato portátil de } \\
\text { documento). }\end{array}$ \\
\hline
\end{tabular}


Embora a plena liberdade criativa tenha pairado em torno da constituição e da formulação dos discursos CTS pelos/as estudantes, observamos uma necessidade premente de associarem os textos da revista a um conteúdo válido, de valor, aceitável pela academia, como a exemplo dos periódicos e sites de pesquisa que não fogem ao rigor do uso da palavra ciência. Assim, em ambas as propostas de nome (levantadas em 9 set. 2015) continha o radical: cientizando e ciência. De outra forma-contéudo, observamos a assunção, pelos/as estudantes, do imaginário sobre o termo escola pública como espaço inalienável de educação. Ou seja, o nome teria que trazer como predicado: escola ou educação. Não importando quais resultados gere socialmente, o qualificativo fora tributado independentemente de conteúdos, de objetivos, de métodos e de avaliações promovidos no espaço escolar. Um imaginário sociocultural que infere sobre uma geopolítica do conhecimento (Maldonado-Torres 2008).

Com isso, destacamos os relatos/depoimentos que seguem:

\begin{abstract}
Aprendi muito a escrever junto com os outros, pois precisávamos conversar e discutir cada detalhe, não era só nossa ideia que importava e tínhamos que conversar e muitas vezes votar na melhor ideia. Foi difícil trabalhar na sala de aula, muitos não estavam nem aí e não faziam nada, mas encontrei pessoas bem estudiosas que me ajudaram muito e isso ajudou (Estudante 1).
\end{abstract}

Demorou muitas reuniões para fazer a revista e ficou um pouco cansativo, o pessoal da turma também não ajuda muito, atrasando os artigos ou nem fazendo direito, mas o grupo foi muito bom e trabalhamos direito, o resultado ficou ótimo e todos gostaram (Estudante 2).

O tempo decorrido entre a aprovação pelo órgão de controle/regulação da Secretaria Municipal de Educação e o anúncio do projeto (reuniões com a direção escolar/pedagógica, com a APP, e com as turmas) gerou um estado de expectativa no grupo de estudantes, uma vez que o projeto só poderia se iniciar após todas as aprovações nos órgãos colegiados e gestores. Ademais, o processo de produção editorial dependeu de decisões coletivas, escolhas, definições, produção de uma pauta conforme o interesse temático das turmas de $9^{\circ}$ ano, e isso gerou a percepção de um trabalho "um pouco cansativo". Além de tudo, os textos teriam que ser revisados, formatados, seguindo o critério de rubricas para publicação (esta foi uma sugestão do Professor e acatada pelo grupo, para qualificação do texto).

A autoria revelada na seleção dos textos: • A força nos movimentos do voleibol; • Força de atrito no tênis; - Força no surf; • A força do soco do Taekwondo e sua reação; • A Física do pênalti; • Ação e reação aplicadas a outras áreas do conhecimento; • Movimentos com velocidade constante; - Acidentes de trânsito e a Física; - A importância do cinto de segurança; • Ação e reação, reforça sentidos de suas vivências esportivas (voleibol, surfe, tênis, futebol, artes marciais), de sua atenção sobre fatos urbanos (trânsito, veículos, segurança no trânsito), ou seja, cumpre a expectativa de saberes situados em discursos CTS. De tal forma-contéudo que foge à lógica de considerar o aparato/produto/artefato tecnocientífico como um fim em si mesmo, ou seja, capitalizado. Porém, o assume com um recurso social, como conhecimento que precisa estar no campo das discussões comunitárias, promovendo interlocução entre a CT e as sociedades, conforme seus sentidos socioculturais.

Em termos do ensino de ciências e tecnologia, essa mudança de olhar pode significar uma transformação radical nos processos cognitivos, na medida em que a atividade tecnocientífica, pensada como atividade meio, passaria a ser orientada por uma lógica distinta da que hoje a estrutura, orientada para a técnica como meio e não um fim em si mesma (Von Linsingen 2007: 3).

Segundo os relatos:

Nossos encontros foram muito legais, fizemos a revista e aprendemos muito de fisica, é difícil entender, mas como estávamos lendo e escrevendo muitas vezes o conteúdo ficava tão fácil que podíamos ajudar nossos amigos. Cada um escreveu 
Ótimo jeito de estudar por que a gente não fica só copiando, tem que estudar, ler e até fomos no laboratório, fizemos um carrinho e vimos a velocidade depois a gente foi escrever e ajudar os amigos a escrever. Na hora de fazer a revista foi muito legal por que gosto muito de computador e ajudei os outros a digitar e colocar as figuras assim a revista ficou bem bonita, isso sim é um trabalho de equipe (Estudante 4).

Saberes situados no campo científico e tecnológico compuseram uma forma-conteúdo socioculturalmente aderida aos sentidos coletivos expressos em um pensamento-linguagem dos/as estudantes. Eis a formação de "um ser de práxis. Somente ele vem sendo um ser de relações num mundo de relações. Sua presença num tal mundo, presença que é um estar com, compreende um permanente defrontar-se com ele." (Freire 2013: 32). Esse confronto se perfez em plena dialogicidade com o objeto de estudo elegido em cada texto, nos quais se aliaram: realidade social - pertenças culturais - espacialidade - práxis em Ciências.

Os processos de textualização constroem objetos de conhecimento ao mesmo tempo em que constroem posições de sujeito. As relações de poder que constituem conhecimentos, também constituem sujeitos, não sem resistências. Conhecer esses processos, portanto, significa conhecer em que posições somos histórico-socialmente colocados e que resistências são aí produzidas pelos mesmos processos. Significa conhecer o que nos constitui, para além de nossas escolhas, enquanto atores educacionais (Silva 2019: 27-28).

Esse processo de textualização pelos/as estudantes vai ao encontro do que Jacinski et al. (2019) atribuem como formação de cidadania sociotécnica, pois, "num contínuo processo de ação e reflexão (práxis), de modo que a interação sociotécnica esteja baseada em ações que valorizem uma sociedade mais justa, inclusiva e sustentável.” (197). E, tais interações sociotécnicas devem se processar entremundos e entremodos de ser e de saber no ensino de ciências, como entendemos mobilizados nesta proposta.

Avaliamos, por fim, que a síntese do que registramos no Quadro 3 produz sentidos de um importante movimento CTS na Educação em Ciências, operando discursivamente dentre negociações de componentes pessoais e não-pessoais no meio sociotécnico, promovendo um cenário de dialogicidade profícuo para o trabalho de produção tecnocientífica, (auto)regulando as relações CTS com o meio interno e externo à escola, formando novos sujeitos sociais e leitores a partir do efeito-leitor sobre temáticas de estudo e problemas operacionais/táticos, bem como mobilizando as categorias freireanas de autonomia, de alteridade e de "subjetividade curiosa, inteligente, interferidora na objetividade", pois "o papel no mundo não é só o de quem constata o que ocorre mas também o de quem intervém como sujeito de ocorrências.” (Freire 1996: 85).

Trocas e compartilhamentos, respeitando identidades e individualidades, compuseram uma ética coletiva, por uma alteridade para a educação em ciências, num ambiente de plena dialogicidade, democracia participativa, solidariedade e ideais coletivos, configuradas nessa IAP.

\section{Considerações finais}

A divulgação tecnocientífica de conteúdos escolares fora tomada em perspectiva discursiva, ou seja, pela forma-conteúdo de linguagens no Ensino Fundamental, em suas múltiplas interlocuções para apreensão de sentidos coletivos de aprendizagens sobre ciência e tecnologia. A proposta se configurou na centralidade do diálogo de saberes sobre a perspectiva de mundo percebidas sob os modos de ser daqueles/as estudantes.

Compreendendo a dimensão tecnocientífica que implicou no valor dessa aprendizagem, o grupo materializou seu fazer-ser social em forma-conteúdo de uma revista, por seus modos de leitura e de escrita, sobre e a partir de suas verdades empíricas. Temas, problemas, culturas, sociedades, sentimentos, relações CTS, formaram o repertório de linguagens gerando seu 
resultado. Ou seja, situaram o seio de inter-relações entremundos e entremodos para a formação de discursos CTS por seus sentidos coletivos.

Nossa credibilidade quanto à abordagem educacional CTS em perspectiva freireana se afirmou no sentido em que os resultados encontrados, tanto como processo quanto como produto final desta proposta, se concretizaram no mesmo sentido em que promoveu posturas cidadãs democraticamente participativas, comunitárias e solidárias. Supriu a contento um processo de Educação em Ciências que se requer transformador, autóctone, decolonial, afirmativo do ser e do saber local, situado em dada regionalidade, voltado a seus problemas comunitários.

Considerando o nível de experiência e curiosidade do grupo editorial, as complexidades tecnocientíficas selecionadas, como temas-problema, reiteraram a importância de formação permanente de sujeitos-leitores, como divulgadores de suas expectativas científicas, de seus modos de ver, de ser e de lidar com a realidade. E, isso conferiu identidade a seus projetos de fazer-ser quanto ao ímpeto de compartilhar socialmente seus conhecimentos, para democratizar a ciência, educando-se e educando cientificamente as sociedades.

Hábitos de leitura, escolhas de literatura, dedicação mais atenta a certas áreas do conhecimento curricular, tudo demonstrou um grupo que se vocaciona para o prosseguimento de estudos, independentemente da área do conhecimento que eleger. Isso requer atenção de políticas de investimento cada vez mais focadas para a Educação Básica, no que se refere à infraestrutura de escolas públicas (laboratórios, espaços de pesquisa), ao incentivo para pesquisa docente, aos projetos de extensão escolar, às parcerias com universidades e institutos, à formação continuada de professores (pós-graduada), são aspectos de um grande objetivo educacional: formar sujeitos-leitores.

Aqui, destacamos a preocupação com uma práxis no fazer científico para afirmar identidades no interior dos processos pedagógicos profissionais, dado o espaço-tempo que conferiu legitimidade ao ser-estudante por seu saber nos discursos CTS. Compreendeu, também, direitos e garantias em uma formação de cidadania propositivamente inclusiva na educação em ciências pela via da metodologia de IAP.

\section{Referências}

Akotirene C. (2019) Interseccionalidade. Feminismos plurais; coord. Djamila Ribeiro. São Paulo: Sueli Carneiro; Pólen. 152 p.

Auler D. (2007) Enfoque Ciência-Tecnologia-Sociedade: pressupostos para o contexto brasileiro. Ciência e Ensino, 1(número especial): 1-20.

Auler D. \& Delizoicov D. (2006) Educação CTS: Articulação entre pressupostos do educador brasileiro Paulo Freire e referenciais ligados ao movimento CTS. Anais do Encontro Iberoamericano Sobre las Relaciones CTS en la Educación Científica. Volume 5. Málaga: Editora da Universidade de Málaga.

Auler D., Strieder R.B., Delizoicov N.C. \& Delizoicov D. (2005) Compreensões de alunos da Educação Básica sobre interações entre CTS. Atas do Encontro Nacional de Pesquisa em Educação em Ciências. Volume 5. Bauru: ABRAPEC.

Busko P.S. \& De-Carvalho R. (2019) Produção autoral de tecnologias sociais por investigaçãoação-participação no ensino de ciências. Revista de Educação, Ciência e Tecnologia, Canoas, 8(1): 1-23. https://doi.org/10.35819/tear.v8.n1.a3321

Cassiani S. \& Von Linsingen I. (2010) Educação CTS em perspectiva discursiva: contribuições dos Estudos Sociais da Ciência e da Tecnologia. Redes, 16(31): 163-182.

Cassiani S., Giraldi P.M. \& Von Linsingen I. (2012) É possível propor a formação de leitores nas disciplinas de Ciências Naturais?: contribuições da análise de discurso para a Educação em Ciências. Educação: Teoria e Prática, 22(40): 43-61.

Correa L.F. \& Bazzo W.A. (2017) Contribuições da abordagem Ciência, Tecnologia e Sociedade para a humanização do Trabalho Docente. Contexto \& Educação, 32(102): 57-80. https://doi.org/10.21527/2179-1309.2017.102.57-80 
Dagnino R. (2019) Tecnociência solidária: um manual estratégico. Marília: Lutas Anticapital. 161 p.

De-Carvalho R. (2019) Sentidos de 'ano-luz' textualizados em linguagem artística (p. 177-209). In: Silva H.C. (Org.). Ciências, seus textos e linguagens: ensaios sobre circulação e textualização de conhecimentos científicos e matemáticos. Curitiba: CRV. 266 p.

Fals Borda O. (2015) Una sociología sentipensante para América Latina. Antología y presentación de Víctor Manuel Moncayo. México, D.F.: Siglo XX; Buenos Aires: CLACSO. 492 p.

Freire P. (1996) Pedagogia da autonomia: saberes necessários à prática educativa. $13^{\circ}$ edição. Coleção leitura. São Paulo: Paz e Terra. 165 p.

Freire P. (2013) Extensão ou comunicação? Trad. de Rosisca Darcy de Oliveira. Recurso digital [epub]. Rio de Janeiro: Paz e Terra. 91 p.

Freitas L.C. (2014) Os reformadores empresariais da educação e a disputa pelo controle do processo pedagógico na escola. Educação \& Sociedade, 35(129): 1085-1114. https://doi.org/10.1590/ES0101-73302014143817

Freire P. (2017) Pedagogia do Oprimido. 63 edição. Rio de Janeiro/São Paulo: Paz e Terra. 253 p.

Galieta T. \& Von Linsingen I. (2019) Educação CTS e temáticas socioambientais: mapeamento dos trabalhos da X e XI jornadas ESOCITE. Anais do Encontro Regional de Ensino de Biologia - RJ/ES. Rio de Janeiro: Colégio de Aplicação/UFRJ.

Giraldi P.M. (2010) Leitura e escrita no ensino de ciências: espaços para produção de autoria. Tese (Programa de Pós-Graduação em Educação Científica e Tecnológica). Universidade Federal de Santa Catarina, Centro de Ciências Físicas e Matemáticas, Centro de Ciências Biológicas, Florianópolis, Santa Catarina.

Jacinski E., Von Linsingen I. \& Corrêa R.F. (2019) Cidadania sociotécnica, tecnologia social e educação CTS (p. 193-207). In: Cassiani S. \& Von Linsingen I. (Orgs). Resistir, (re)existir e (re)inventar a educação científica e tecnológica. Recurso digital [E-book]. Florianópolis: UFSC/CED/NUP. 401 p.

Maldonado-Torres N. (2008) A topologia do Ser e a geopolítica do conhecimento. modernidade, império e colonialidade. Revista Crítica de Ciências Sociais, 80: 71-114. https://doi.org/10.4000/rccs.695

Mato D. (2014) No 'estudiar al subalterno', sino estudiar con grupos sociales 'subalternos' o, al menos, estudiar articulaciones hegemónicas de poder. Desafios, 26(1): 237-264. https://doi.org/10.12804/desafios26.1.2014

Mota Neto J.C. (2018) Por uma pedagogia decolonial na América Latina: convergências entre a educação popular e a investigação-ação participativa. Arquivos Analíticos de Políticas Educativas, 26(84): 1-17. http://dx.doi.org/10.14507/epaa.26.3424

Oliveira M.C.D. \& Von Linsingen I. (2019) Reflexões acerca da Educação CTS Latino-americana a partir das discussões do grupo de pesquisa DiCiTE da UFSC (p. 177-191). In: Cassiani S. \& Von Linsingen I. (Orgs). Resistir, (re)existir e (re)inventar a educação científica e tecnológica. Recurso digital [E-book]. Florianópolis: UFSC/CED/NUP. 401 p.

Orlandi E.P. (2012) Divulgação científica e efeito leitor: uma política social urbana (p. 149-162). In: Orlandi E.P. (Ed.) Discurso e texto: formulação e circulação dos sentidos. $4^{\circ}$ edição. Campinas, SP: Pontes. $218 \mathrm{p}$.

Quijano A. (2005) Colonialidade do poder, Eurocentrismo e América Latina (p. 117-142). In: Lander E. (Org.). A colonialidade do saber: eurocentrismo e ciências sociais: perspectivas latinoamericanas. Buenos Aires: Colección Sur Sur, CLACSO. 130 p.

Renaud D. \& Sánchez C. (2015) Lembranças e histórias de um vale encantado: a educação ambiental popular através da metodologia investigação-ação-participante (IAP) na proteção de saberes locais no Vale do Jequitinhonha. Anais do Encontro Pesquisa em Educação Ambiental. Volume 8. Rio de Janeiro: UFRJ, UFFRJ, UNIRio, FFCLRP/USP.

Rodrigues V.A.B., Von Linsingen I. \& Cassiani S. (2019) Formação cidadã na educação científica e tecnológica: olhares críticos e decoloniais para as abordagens CTS. Revista Educação e Fronteiras On-Line, 9(25): 71-91. https://doi.org/10.30612/eduf.v9i25.11012 
Schwan G. \& Santos R.A. (2020) Dimensionamentos curriculares de enfoque CTS no ensino de ciências na educação básica. Revista de Estudos e Pesquisas sobre Ensino Tecnológico, 6: 114. https://doi.org/10.31417/educitec.v6i.981

Silva H.C. (2006) O que é divulgação científica? Ciência \& Ensino, 1(1): 53-59.

Silva H.C. (2019) A noção de textualização do conhecimento científico: veredas pelos Estudos da Ciência, conexões pela Educação em Ciências (p. 15-34). In: Silva H.C. (Org.). Ciências, seus textos e linguagens: ensaios sobre circulação e textualização de conhecimento científicos e matemáticos. Curitiba: CRV. 266 p.

Silveira J.C., Cassiani S. \& Von Linsingen I. (2018) Escrita e autoria em texto de iniciação científica no ensino fundamental: uma outra relação com o saber é possível? Ciência $e$ Educação, 24: 9-25. https://doi.org/10.1590/1516-731320180010002

Von Linsingen I. (2007) Perspectiva educacional CTS: aspectos de um campo em consolidação na América Latina. Ciência \& Ensino, 1(número especial): 1-19. 